\title{
Conditioning of simultaneous and serial feature-positive discriminations
}

\author{
ROBERT T. ROSS and PETER C. HOLLAND \\ University of Pittsburgh, Pittsburgh, Pennsylvania 15260
}

\begin{abstract}
Three experiments with rat subjects examined the development of simultaneous and serial feature-positive discriminations in appetitive conditioning. In Experiment 1, reinforced presentations of a simultaneous light-tone compound were intermixed with nonreinforced presentations of either the light or the tone. The compound stimulus acquired conditioned behaviors of a form characteristic of the predictive feature alone; the element common to reinforced and nonreinforced trials did not evoke conditioned behavior. In Experiment 2, reinforced presentations of a serial light-trace-tone compound were intermixed with nonreinforced tonealone presentations. The light feature stimulus acquired conditioned behaviors characteristic of visual CSs. The tone stimulus, common to reinforced and nonreinforced trials, evoked conditioned behaviors characteristic of auditory CSs, but only when preceded by the light. In Experiment 3, variations in the interval between the light and tone on reinforced trials had little effect on responding to the light CS but substantially altered the pattern of responding to the tone CS. These results suggested that simultaneous and serial featurepositive discriminations may be solved differently. Performance in simultaneous featurepositive discriminations may be determined solely by associations between the feature stimulus and the reinforcer, but performance in serial discriminations may also involve the acquisition of a conditional cue function to the feature.
\end{abstract}

In a feature-positive discrimination, a compound stimulus $(\mathrm{AB})$ is reinforced, but one of its elements (A) is separately nonreinforced (Jenkins \& Sainsbury, 1969). This procedure can be described as a simple conditional discrimination, since the significance of the common element $\mathbf{A}$ depends on the presence of the feature $B$. The feature-positive procedure has attracted little attention as a conditional discrimination, however, because it may be described more simply as a feature-present vs. feature-absent discrimination (but see Bottjer \& Hearst, 1979). In fact, when tests of responding to feature and common elements presented individually are administered after featurepositive training, only the feature stimulus acquires consistent control of behavior (e.g., Hearst, 1978). This acquisition of responding to a consistent predictor of reinforcement, but not a simultaneously presented less valid stimulus, is consistent with a number of recent theories of conditioning (e.g., Mackintosh, 1975; Rescorla \& Wagner, 1972).

Somewhat different outcomes have been reported when the feature and common elements are presented serially rather than simultaneously on reinforced compound trials. For instance, Looney and Griffin (1978) presented pigeons with food-reinforced tonekeylight serial compound trials and nonreinforced keylight-alone trials in autoshaping. By the end of training, the pigeons responded to the keylight com-

This research was supported in part by Grant BNS 79-03853 from the National Science Foundation. Reprints are not available. mon element, rather than to the tone feature, but only when that keylight was preceded by the tone feature stimulus. Similarly, Bottjer and Hearst (1979), in pigeon autoshaping, and Terry and Wagner (1975), in rabbit eyelid conditioning, signaled whether or not a conditioned stimulus (CS) would be paired with an unconditioned stimulus (US) by preceding reinforced CSs with an extra, "preparatory" US. In both experiments, subjects mastered the discriminations, responding more to the CS (common element) when it was preceded by the preparatory US (feature) than when it occurred alone.

Thus, in these serial feature-positive discriminations, conditioned responding occurred to the less valid common element rather than to the feature that consistently predicted reinforcement. Konorski (1967), however, suggested that performance in serial discriminations like these was in fact governed by associations between the more valid feature stimulus and the reinforcer: The subsequent common element merely "released" behaviors conditioned to that feature, rather than itself being associated with the reinforcer. Alternately, the feature stimulus may acquire an ability to activate an association between the common element and the reinforcer, thereby "setting the occasion" for responding to the element (e.g., Holland, in press; Moore, Newman, \& Glasgow, 1969). Finally, an association may be formed between a configural cue unique to the feature-common element sequence and the reinforcer (e.g., Razran, 1971; Rescorla, 1972). 
The experiments reported here examined the associative basis of successful performance of both simultaneous and serial feature-positive discriminations. These experiments used rat subjects in an appetitive conditioning situation in which the form of conditioned behaviors depends on the nature of the CS (Holland, 1977). The use of a reinforced compound stimulus consisting of auditory and visual elements that evoke very different patterns of behavior permitted easy identification of the source of conditioned responding during presentation of the stimulus compounds (Holland, 1977, Experiment 2). In Experiment 1, a light-tone simultaneous compound was reinforced with a food US, while the light, the tone, or neither element was separately nonreinforced. Experiment 2 examined performance on a serial feature-positive discrimination between reinforced light-trace-tone serial compound and nonreinforced tone-alone presentations. Experiment 3 examined the effects of variations in the feature-common element interval on the form of conditioned behavior.

\section{EXPERIMENT 1}

Experiment 1 examined performance in simultaneous light-tone feature-positive discriminations. Three groups of rats all received reinforced presentations of a 5-sec simultaneous light-tone compound CS. One group also received intermixed, nonreinforced presentations of the tone alone; a second group received nonreinforced light presentations; and the third group received no other stimulus presentations. Thus, in the first group, the predictive feature was the light; in the second group, the tone was the feature stimulus; and, in the third group, both stimuli equally predicted food delivery. If only the feature stimulus controls responding in simultaneous feature-positive discriminations, the form of responding to the compound should differ among the groups. Finally, all rats received a test session in which responding to the lighttone compound, the light alone, and the tone alone were assessed.

\section{Method}

Subjects and Apparatus. The subjects were 24 male SpragueDawley rats maintained at $80 \%$ of their ad-lib weights. The rats were about 120 days old at the beginning of the experiment; they had no previous experimental history.

Four chambers, $22.9 \times 20.3 \times 20.3 \mathrm{~cm}$ with clear acrylic sides and aluminum front and rear walls, were used. Each chamber contained a recessed food magazine on the front wall, with a constantly illuminated 6-W lamp directly above it. The chambers were enclosed in sound-insulated compartments with $30 \times 30 \mathrm{~cm}$ clear acrylic windows to permit behavioral observation. A 6-W lamp, for use as a visual CS, was mounted in each compartment $10 \mathrm{~cm}$ above the rear acrylic wall. A speaker for auditory CS delivery was mounted to the left of the lamp. Behavior was recorded by a low-light television camera, positioned $2.1 \mathrm{~m}$ from the enclosure, which included all four experimental chambers within its view.
Behavioral observation procedures. Behavioral observations were made from videotapes. Observation procedures were initiated with the onset of the CS. Two observation procedures were used. The first procedure was used to score data in the acquisition phase. Beginning with the first rat in the group, one behavior was recorded, and then the observer shifted his gaze to the next rat in the group. This shift occurred every $1.25 \mathrm{sec}$ and was aided by timed auditory signals superimposed on the tape. Thus, each rat's behavior was sampled once in each 5 -sec time interval during the course of a trial. The second, more detailed procedure was used to score data from the test session. In this procedure, each rat's behavior was judged four times in each 5-sec interval, again aided by the auditory signals. In addition, in both procedures the occurrence of startle behavior (see below) during the 1.25-sec interval after CS onset was recorded for all rats. The absolute frequency of each behavior, except startle, was converted into a percentage of the total number of behavioral observations in order to facilitate within- and across-experiment comparisons in which different numbers of trials or observations were used. The measure of startle responding used was the percentage of trials on which that behavior occurred.

The categories of behavior used here have been described in detail elsewhere (Holland, 1977, 1980). The categories of principal interest in this study were: (1) startle-a sudden gross body movement (often a jump) resulting in a change in position, typically occurring within 1.25-sec of an auditory CS presentation; (2) headjerk-short, rapid, horizontal and/or vertical movements of the head, often directed toward the food magazine; (3) rear-standing on the hind legs, with both front feet off the grid floor, but not engaging in grooming behavior. (4) magazine-standing motionless in front of the food magazine, with nose or head within the magazine. Previous experiments (e.g., Holland, 1977) have shown that auditory CSs evoke startle, head-jerk, and some magazine behaviors, but visual CSs evoke rear and magazine behaviors. A number of other behavioral categories were also recorded, such as "quiet" and "walk" (see Holland, 1977, for complete descriptions), but are not systematically reported in the present study.

A single observer scored the videotapes in Experiment 1. However, to assess the objectivity of his scoring, data from the test session were also scored by another observer unaware of the group designations or the purpose of the experiment. The two observers agreed on $96 \%$ of 240 joint observations.

Procedure. Rats were first trained to eat from the food magazine. Ten deliveries of two 45-mg Noyes pellets each were given on a variable-time 1-min (VT 1-min) schedule.

The rats then received pairings of a 5 -sec light-tone compound stimulus with the delivery of two food pellets over the course of 1280 -min sessions. The light element was an intermittent $(2 / \mathrm{sec})$ flashing of the houselight; the tone was $1,500 \mathrm{~Hz}$ and was not intermittent. All rats received four reinforced compound presentations in each of the first four sessions and two reinforced compound presentations in each of the last eight sessions. In addition, Group $T$ (in which the tone element was the more consistent predictor of food) received four nonreinforced presentations of the light in each of the first four sessions and six such presentations in each of the last eight sessions. Similarly, Group L (in which the light element was the more consistent predictor of food) received four nonreinforced presentations of the tone in each of the four sessions and six such presentations in each of the last eight sessions. Compound and element trials were intermixed randomly in both groups. Group LT (in which the light and tone were equally predictive of reinforcement) received only reinforced compound presentations.

All rats then received a single 80 -min test session in which three presentations each of the light, tone, and light-tone compound stimuli were given, all nonreinforced, in random order.

Many important statistical comparisons in these experiments involved groups of rats that exhibited virtually no instances of certain behaviors. Because of several extreme cases of heteroge- 
neity of variances, we used distribution-freen methods of data analysis throughout these experiments. All measures of central tendency given are medians. Unless otherwise noted, all statistical tests used the $p<.05$ level of significance.

\section{Results and Discussion}

Figure 1 shows behaviors occurring in response to the reinforced compound and nonreinforced element stimuli during the conditioning phase. The featurepositive discriminations were acquired rapidly in both Group L and Group T. By the end of the conditioning phase, neither the nonreinforced tone in Group $\mathrm{L}$ nor the nonreinforced light in Group $\mathrm{T}$ evoked appreciable amounts of any conditioned behavior. Behaviors acquired in response to the compound CS were characteristic of the stimulus modality of its predictive element. That is, Group T (in which the tone was the more valid predictor of food) acquired behaviors characteristic of auditory CSs-startle, head-jerk, and magazine; Group L (in which only the light was a consistent predictor of food) acquired rear and magazine behaviors characteristic of visual CSs; and Group LT (in which the light and tone were equally valid predictors of food) acquired all four behaviors. Thus, the greater the relative validity of a stimulus element, the more that stimulus determined the form of responding to the compound. Analyses on responding over the entire conditioning phase, using Miller's method of multiple comparisons (in Hollander \& Wolfe, 1973), showed that startle and head-jerk behaviors were more frequent in Group $\mathrm{T}$ than in Group LT or Group L and more frequent in Group LT than in Group L. Similarly, Group L showed more rear behavior than did Group LT, which in turn showed more than Group T. Magazine behavior (evoked by both auditory and visual stimuli) did not differ among the groups.

Table 1 shows the results of the test session in which rats in all three groups received nonreinforced presentations of the light-tone compound, the tone, and the light stimuli. Responding to the compound CS closely resembled that observed in the conditioning phase. More important, responding to the compound was entirely attributable to conditioning to the more valid element. Not only did the previously nonreinforced elements in Groups $\mathrm{L}$ and $\mathrm{T}$ elicit no conditioned behaviors, but also responding to the predictive element alone was similar to responding to the compound. The only reliable valid-element vs. compound difference in those two groups was in rear behavior in Group L; that behavior was more frequent in responding to the light alone (Wilcoxon $\mathrm{T}$ =3.5). Similarly, in Group LT, both the tone and the light separately evoked conditioned behaviors ap-
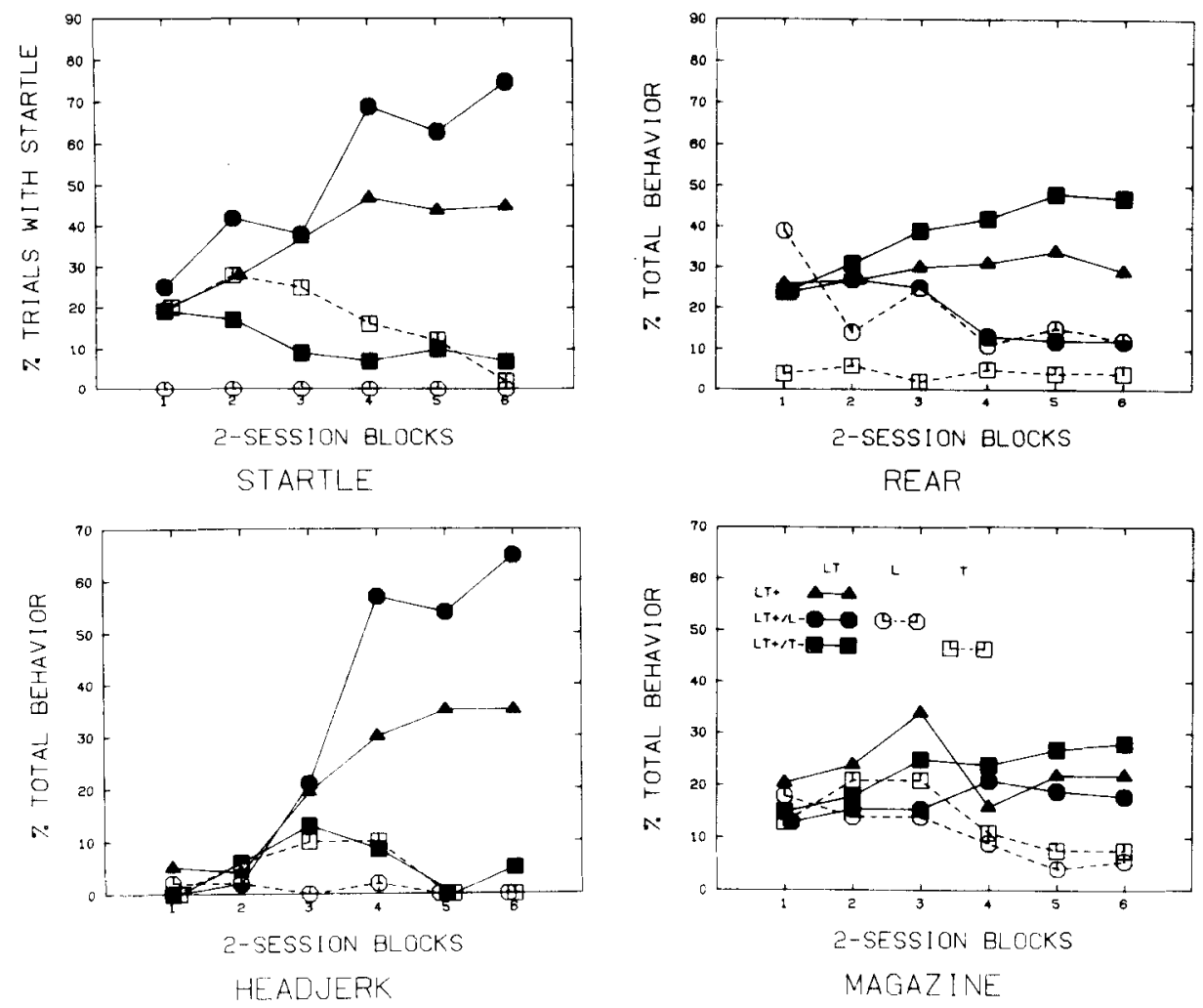

Figure 1. Behaviors during the discrimination phase of Experiment 1. LT = light-tone compound, $L=$ light, and $T=$ tone. 
Table 1

Test Session Responding in Experiment 1

\begin{tabular}{|c|c|c|c|c|c|c|c|c|c|c|c|c|}
\hline \multirow[b]{2}{*}{ Group } & \multicolumn{3}{|c|}{ Startle } & \multicolumn{3}{|c|}{ Head Jerk } & \multicolumn{3}{|c|}{ Rear } & \multicolumn{3}{|c|}{ Magazine } \\
\hline & $\mathbf{L}$ & LT & $\mathrm{T}$ & $\mathrm{L}$ & LT & $\mathbf{T}$ & L & LT & $\mathrm{T}$ & $\mathbf{L}$ & LT & $\mathrm{T}$ \\
\hline LT & 0 & 45 & 51 & 3 & 29 & 40 & 40 & 24 & 7 & 20 & 25 & 22 \\
\hline $\mathbf{L}$ & 0 & 5 & 7 & 0 & 0 & 0 & 78 & 57 & 7 & 11 & 24 & 20 \\
\hline $\mathrm{T}$ & 0 & 68 & 80 & 0 & 56 & 64 & 12 & 11 & 2 & 8 & 25 & 22 \\
\hline
\end{tabular}

Note-Entries for startle responding signify the median percentage trials on which a startle response occurred. Entries for the other three behaviors are median percentages of total behavior. $L=$ light,$T=$ tone, $L T=$ light-tone compound.

propriate to CŚs of those modalities (Holland, 1977).

Finally, as was the case with compound responding in the conditioning phase, the frequency of each conditioned behavior category was determined by the relative validity of the stimulus normally responsible for that behavior. Multiple comparisons between groups showed that startle and head-jerk behaviors in response to both the light-tone compound and the tone alone were most frequent in Group $\mathrm{T}$, of intermediate frequency in Group LT, and least frequent in Group L. Similarly, rear behavior in response to the light was most frequent in Group L, of intermediate frequency in Group LT, and least frequent in Group T; rearing in response to the light-tone compound was reliably more frequent in Group $L$ than in Group LT or Group T, but the difference between Group LT and Group T was not significant.

In summary, the similarity of the forms of the conditioned responses to the compound and feature stimuli indicated that associations were established to the feature, rather than to the common, element. Furthermore, the similarity of the magnitudes of those responses suggested that no appeal to associations with a unique, configural cue is necessary. Finally, the occurrence of topographically distinct CRs to the physically identical light-tone compound in the three groups also argues against the importance of a configural cue.

\section{EXPERIMENT 2}

Experiment 2 examined performance in a serial feature-positive discrimination. A 5-sec tone was reinforced with a food US only when it was preceded by a 5-sec light feature stimulus. When the tone was not preceded by the light feature, no US was delivered. Control rats received separate presentations of the light and tone. Those rats received the same pattern of reinforced and nonreinforced tones as the rats receiving discrimination training, but the reinforced tones were not signaled by light presentations. Instead, light CSs were reinforced separately.

\section{Method}

Subjects and Apparatus. The subjects were 16 male and 4 female Sprague-Dawley rats maintained at $80 \%$ of their ad-lib weights. The female rats were approximately 100 days old and were experimentally naive at the start of the experiment. The male rats were approximately 150 days old and had had previous experience in a flavor-aversion study. No differences in behavior between male and female rats were detected during the study. The apparatus was that used in Experiment 1.

Procedure. In the first session, all rats received 10 deliveries of two $45-\mathrm{mg}$ food pellets on a VT 1 -min schedule to train them to eat from the magazine. The next 2 days served as a pretest of the stimuli to be used in conditioning. On both days, all rats received four 5 -sec presentations of the 6-W flashing $(2 / \mathrm{sec})$ houselight CS and four 5 -sec presentations of a $1,500-\mathrm{Hz}$ tone $\mathrm{CS}$, in random order. These and all subsequent sessions were $75 \mathrm{~min}$ long.

On the following day, training designed to establish a serial feature positive discrimination in Group $D$ was initiated. The rats in Group $D$ ( $n=12$, eight males and four females) received two types of trials. Feature trials $(\mathrm{T}+$ ) consisted of the $5-\mathrm{sec}$ light feature followed $25 \mathrm{sec}$ later (onset to onset) by the 5 -sec tone, which terminated with the delivery of two $45-\mathrm{mg}$ food pellets. The common-element alone trials ( $\mathrm{T}-$ ) consisted of the same 5-sec $1,500-\mathrm{Hz}$ tone without food delivery. The two types of trials were intermixed randomly in each session; the intertrial intervals varied from 5.3 to $11.3 \mathrm{~min}$ (mean=8.3). For the first 5 days of discrimination training, the rats in Group D received four reinforced $\mathrm{T}+$ trials and four nonreinforced $\mathrm{T}-$ trials during each session. On Days 6 to 25 , the rats received two reinforced $T+$ and six nonreinforced $\mathrm{T}$ - trials.

During the discrimination phase, the eight control rats in Group $\mathrm{C}$ received three kinds of trials. Five-second $1,500-\mathrm{Hz}$ tones either were followed immediately by food delivery or were not reinforced; 5-sec flashing light presentations were followed $30 \mathrm{sec}$ later (onset to onset) by food delivery. The three trial types were intermixed randomly in each session. For the first five sessions, the rats in Group $\mathrm{C}$ received four reinforced tone trials, four nonreinforced tone trials, and four reinforced light trials. The intertrial intervals ranged from 3.8 to $7.8 \mathrm{~min}$ (mean $=5.8$ ) in these sessions. The rats received two reinforced light trials, two reinforced tone trials, and six nonreinforced tone trials in the remaining 20 sessions. The intertrial intervals varied from 3.8 to 9.8 min (mean $=6.8$ ) in those sessions. Thus, rats in Group C received the same number and pattern of reinforced and nonreinforced tones with lights as the rats in Group D. Group C was not run concurrently with Group $D$, but the subjects were drawn from similar populations and were otherwise treated identically to those in Group D.

Finally, the rats in both groups received two test sessions in which four nonreinforced tone trials and four nonreinforced lightalone trials were presented in random sequence.

Behavioral observations were made using the less detailed procedure of Experiment 1. On serial compound trials, observations were made throughout the trace interval as well as during light and tone presentations.

\section{Results}

Pretest. Table 2 shows behaviors in response to the tone and light during the two pretest sessions. There were no reliable differences between Group $\mathrm{C}$ and 
Table 2

Pretest Responding in Experiment 2

\begin{tabular}{lcccc} 
& \multicolumn{2}{c}{ Group D } & \multicolumn{2}{c}{ Group C } \\
\cline { 2 - 5 } & Tone & Light & Tone & Light \\
\hline Rear & 0 & 28 & 6 & 28 \\
Magazine & 21 & 15 & 19 & 17 \\
Head Jerk & 1 & 0 & 2 & 0 \\
Startle & 9 & 0 & 12 & 0 \\
\hline
\end{tabular}

Note-Entries for startle responding indicate the percentage of trials on which a startle response occurred. Entries for the other three behaviors indicate percentages of total behavior.

Group D in the frequency of any of the behaviors.

Discrimination training. Responding characteristic of visual stimuli developed in response to the light over the course of discrimination training in both groups. Rear behavior rose from $8 \%$ of total behavior over the first two sessions to $48 \%$ over the last two sessions in Group D and from $8 \%$ to $32 \%$ in Group C. Similarly, magazine behavior during the trace interval between light and tone presentations increased from $16 \%$ to $36 \%$ in Group D and from $18 \%$ to $40 \%$ in Group C. Other experiments (Holland, 1980) show that US-related magazine responding primarily occurs later in the CS-US interval; the frequency of magazine behavior during the light itself decreased from $19 \%$ to $5 \%$ in Group D and from $16 \%$ to $14 \%$ in Group C. There were no reliable differences in rear or magazine behaviors between the two groups.

The tone CSs acquired behaviors characteristic of auditory CSs in both groups. Figure 2 shows headjerk, startle, and magazine behaviors occurring during the tone on both reinforced $(\mathrm{T}+$ ) serial compound trials and nonreinforced $(\mathrm{T}-)$ tone-alone trials in Group D and during all tone presentations in Group C. In Group D, the tone initially acquired all three behaviors both when presented alone and when presented with the serial compound. By the end of training, however, 11 of the 12 rats in Group D showed more head-jerk behavior (top panel) in response to the tone on $\mathrm{T}+$ trials than on $\mathrm{T}-$ trials (the 12 th rat showed no head-jerk behavior in this experiment).

The two lower panels of Figure 2 show startle and magazine behaviors in response to the tone. In Group D, both of those behaviors were acquired rapidly and then decreased to lower levels; neither was differentially elicited by the tone on $\mathrm{T}+\mathrm{vs.} \mathrm{T}-$ trials. The loss of magazine responding to a reinforced auditory stimulus is typical (e.g., Holland, 1977) and is described most simply as the replacement of magazine behavior by head-jerk behavior (note that in Figure 1, the decrease in magazine behavior coincides with the initial acquisition of headjerk responding). Conversely, the loss of startle responding to the reinforced tone in Group D is unusual and is discussed below. Finally, rear behavior was not acquired in response to the tone in Group D; over the last two sessions, rear constituted $3 \%$ of the behavior in response to tone-alone trials and $0 \%$ of the behavior in response to the tone on lighttone trials.

In Group C, moderate levels of startle, head-jerk, and magazine behaviors were acquired and maintained; rear behavior made up only $8 \%$ of the total behavior (over the last two sessions). Over the entire discrimination phase, Group $\mathrm{C}$ showed reliably less head-jerk behavior during the tone than did Group D on $\mathrm{T}+$ trials (Mann-Whitney $U=12.5$ ) but reliably more startle $(U=2)$ responding.

Test. Figure 3 shows rear, magazine, and head-jerk behaviors during the test phase. Responding during
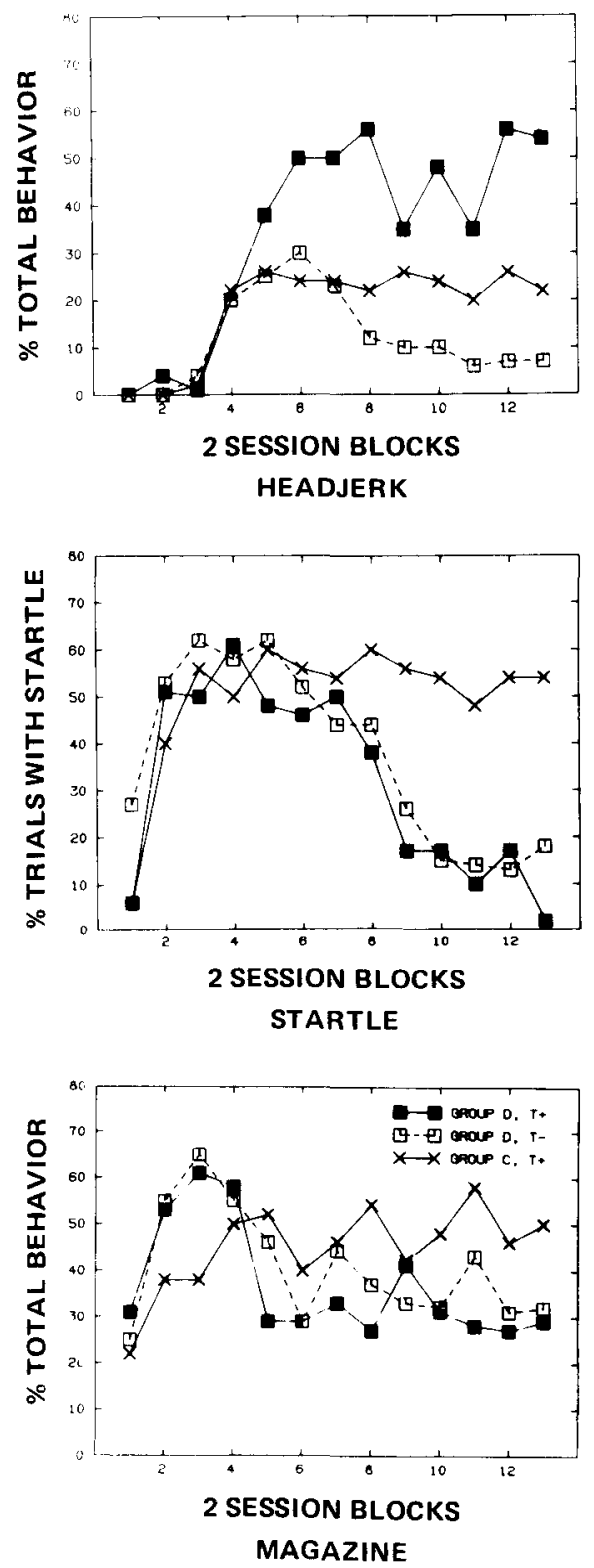

Figure 2. Behaviors in response to the reinforced $(T+)$ and nonreinforced (T-) tones in Group D and to all tones in Group D during the discrimination phase of Experiment 2. 


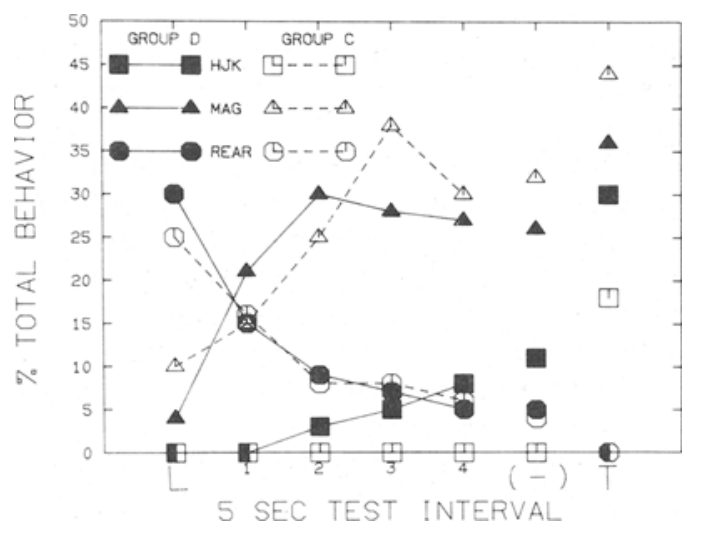

Figure 3. Behaviors occurring during the teat phase of Experimeat 2. Note that responding during the light and the four 5-sec trace intervals is combined over light-tone and light-alone trials. $L=1 i g h t, T=$ tone, and $(-)=$ the 5-sec interval during light-tone trials in which tone would normally be delivered in Group D.

the light and the four 5-sec trace intervals after the light is combined across both light-tone and lightalone trials. Responding to the tone on light-tone trials is indicated by "T," and responding during the fifth 5 -sec interval on light-alone trials (corresponding to the time at which the tone would be delivered on light-tone trials in Group D) is indicated by "-".

In both groups, the light stimulus evoked substantial rear behavior, which was subsequently replaced by magazine behavior during the postlight trace intervals. This pattern was similar to that occurring in prior discrimination training. More important is a comparison of responding during the tone on lighttone trials with that occurring during the fifth 5-sec interval after the light on light-alone trials. All 11 of the rats that displayed head-jerk behavior in Group D showed more of that behavior during the tone than during the corresponding trace interval. Thus, the occurrence of high levels of head-jerk behavior in response to the tone on light-tone trials in Group D was dependent on the tone's presence. Similarly, magazine behavior was marginally more frequent (sign test $p=.09$ ) during the tone than during the corresponding trace interval. Finally, responding in Group $C$ during testing was similar to that in Group D except that substantially more startle responding (42\% vs. $0 \%, U=0$ ) occurred in response to the tone.

\section{Discussion}

Rats in Group D readily solved a serial featurepositive discrimination. The visual feature stimulus acquired rear and magazine behaviors characteristic of visual CSs. Furthermore, the tone common-element stimulus evoked head-jerk behavior (characteristic of auditory CSs) when preceded by the light, but not when presented alone.

The occurrence of auditory- rather than visualcharacteristic behaviors to the tone in Group D in- dicates that the tone did not merely "release" behavior conditioned to the more predictive visual feature stimulus. Nor was terminal performance due solely to the tone's acquiring its own conditioning, since the tone alone did not evoke tone-specific head-jerk behavior. Instead, the light (in addition to evoking its own CR) appeared to acquire a conditional cue function as if "setting the occasion" (Moore et al., 1969) for responding to the tone. That is, rather than the tone's signaling when to respond based on associations with the light feature stimulus, the light seemed to signal when a relation between the tone and the US held. Alternately, the rats may have constructed a configural cue unique to the compound of the tone and the trace aftereffects of the light (Experiment 3 considers this possibility further).

It might be argued that the occurrence of conditioned behavior in response to the tone only when it was preceded by the light was the result of summation of subthreshold response tendencies to the tone with conditioning to the light. This account seems unlikely: first, because the difference between head-jerk behavior evoked by the tone-alone vs. the tone on light-tone trials was so large; second, because the light had no such summative effect on headjerk behaviors in response to the tone in Group $C$ in testing; and, third, because other experiments (Holland, 1977, Experiment 3) indicate that although the associative strengths of auditory and visual stimuli summate, their response tendencies compete with each other.

One feature of the data in Experiment 2 deserves further comment. Startle behavior in response to the tone within the light-tone compound in Group D showed a bitonic acquisition function. Not only was such a loss not observed in Group $\mathrm{C}$ or in previous experiments (e.g., Holland, 1977), but also it weakens the "occasion-setting" account described above: If the light sets the occasion for responding to the tone, why doesn't that tone evoke startle responding as do separately reinforced tones? It is likely that the loss of startle responding in Group D was the result of the formation of associations between the light and the tone. Recently, Holland and Ross (1981) found a similar lack of startle behavior in response to auditory stimuli when a visual-then-auditory serial compound stimulus was followed by a food US. They suggested that light-tone associations might enable the light to evoke a representation of the tone stimulus. Within a theory such as Wagner's (1978), such evocation of a representation of the tone would "prime" it into a working memory. The subsequent occurrence of a tone already represented in working memory would be less surprising than the occurrence of an unsignaled tone and might, therefore, be less likely to evoke a startle response.

Finally, the results of a pilot experiment extended the generality of the findings of Experiment 1. Four 
rats received serial feature-positive discrimination training identical to that administered to Group D in Experiment 2 except that the tone served as the feature and the light served as the common element. The pattern of responding obtained paralleled the present results: The feature tone elicited startle and head-jerk behavior, and the light common element evoked rear behavior, but only when preceded by the tone.

\section{EXPERIMENT 3}

In Experiment 2, rats displayed substantial behavior in response to the common tone stimulus rather than confining responding to the more predictive light feature stimulus as in Experiment 1. An obvious difference between Experiments 1 and 2 is the serial nature of stimulus presentation in Experiment 2. Experiment 3 examined the role of the interval between the feature stimulus and the reinforced common stimulus in generating behavior in feature-positive discriminations. Five groups of rats received reinforced light-tone trials in which the interval between stimulus onsets ranged from $0 \mathrm{sec}$ (simultaneous) to $20 \mathrm{sec}$; as in Experiment 2, tone-alone trials were not reinforced.

\section{Method}

Subjects and Apparatus. The subjects were 40 female SpragueDawley rats maintained at $80 \%$ of their ad-lib weights. Twenty of the subjects were experimentally naive, while the remainder had had previous experience in a flavor-aversion study. No differences between the behaviors of naive and experienced rats were detected over the course of the study. The apparatus and stimuli were identical to those described in Experiments 1 and 2.

Procedure. Initially, all rats received magazine training and two pretest sessions identical to those of Experiment 2. On the next day, eight rats (four naive and four experienced) were assigned to each of five groups, and training designed to establish the featurepositive discriminations was begun. Two types of trials were used. Light-tone compound trials consisted of the 5 -sec flashing $(2 / \mathrm{sec})$ light feature stimulus whose onset was followed $0,5,10,15$, or $20 \mathrm{sec}$ later by the $5-\sec 1,500-\mathrm{Hz}$ tone in Groups $0,5,10$, 15 , and 20 , respectively. Two $45-\mathrm{mg}$ food pellets were delivered at the termination of the tone. All groups also received nonreinforced tone-alone trials. Trials were intermixed randomly with a variable intertrial interval during the $75-\mathrm{min}$ sessions, as in Experiments 1 and 2 . For the first 5 days of conditioning, all rats received four light-tone and four tone-alone trials. In the remaining sessions, all groups received two light-tone and six tonealone trials.

Behavioral observations were made as in Experiment 2. However, a different procedure for assessing the objectivity of the data scoring was used because a naive observer was not available. Instead, one observer constructed a videotape sampling both reinforced and nonreinforced tone presentations in all groups. A second observer then scored that tape without knowledge of the type of trials being scored. That observer agreed with the primary observer on $94 \%$ of 200 joint observations.

\section{Results}

Pretest. Over the course of the 2 days of pretesting, $34 \%$ of the behavior evoked by the light was rear, $16 \%$ was magazine, and $50 \%$ was quiet; no head-jerk or startle responding was observed. Behavior in response to the tone was $3 \%$ rear, $17 \%$ magazine, and $80 \%$ quiet; startle behavior occurred on $10 \%$ of the tone trials.

Discrimination training. Rear behaviors in response to the light feature increased over the course of acquisition (Figure 4); Page tests of increasing trend (in Hollander \& Wolfe, 1973) for all groups combined and each group individually were reliable $(L * s>5.3)$. A Kruskal-Wallis test revealed no reliable effect of light-tone (or light-food) interval on rear behavior. This lack of an interval function is surprising since Holland (1980) found a well-defined interval function for rear behavior in nondifferential conditioning: Rear behavior was more frequent with 10-sec CS-US intervals (as in Group 5 here) than with longer or shorter intervals. Perhaps the presence of the tone immediately before US delivery effectively flattened the CS-US interval function, as Kehoe, Gibbs, Garcia, and Gormezano (1979) observed in rabbit nictitating membrane conditioning.

As in Experiment 1, magazine behavior in response to the light itself did not increase over the course of discrimination training, but that behavior did become more frequent during the trace intervals between light and tone presentation (in the groups having such intervals). The top portion of Table 3 shows magazine behavior during the final two discrimination sessions. Finally, head-jerk behavior also emerged in the trace intervals, especially during the later portions of those intervals (Table 3, lower portion).

The acquisition of responding to the tone is shown in Figure 5. The top two panels display head-jerk behavior in response to the tone occurring within lighttone compounds ( $T+$, left panel) and the tone occurring alone ( $\mathrm{T}-$, right panel). The frequency of head-jerk behavior in response to $\mathrm{T}+$ differed among the groups over all sessions of discrimination training $(H=21.65)$. Multiple comparisons using Miller's

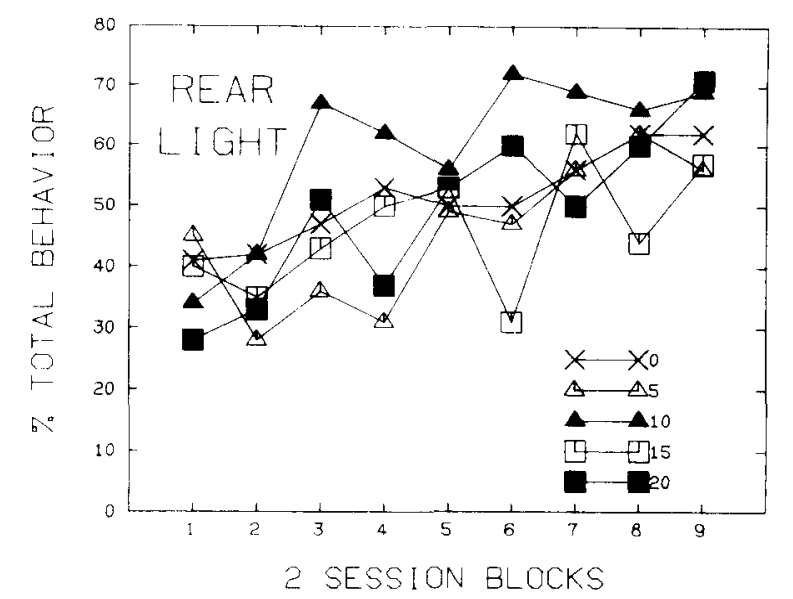

Figure 4. Rear behavior in response to the light feature in Experiment 3. 
Table 3

Behaviors During the Light, the Tone, and Intervening Trace Intervals in Experiment 2

\begin{tabular}{|c|c|c|c|c|c|c|c|c|c|c|}
\hline \multirow[b]{2}{*}{ Group } & \multicolumn{5}{|c|}{ Magazine Behavior } & \multicolumn{5}{|c|}{ Head Jerk Behavior } \\
\hline & $\mathrm{L}$ & 1 & 2 & 3 & $\mathrm{~T}$ & $\mathbf{L}$ & 1 & 2 & 3 & $\mathrm{~T}$ \\
\hline 0 & 19 & & & & 19 & 9 & & & & 8 \\
\hline 5 & 19 & & & & 47 & 0 & & & & 34 \\
\hline 10 & 12 & 34 & & & 20 & 0 & 34 & & & 65 \\
\hline 15 & 9 & 25 & 31 & & 16 & 0 & 12 & 31 & & 63 \\
\hline 20 & 0 & 38 & 12 & 16 & 21 & 0 & 9 & 16 & 37 & 66 \\
\hline
\end{tabular}

Note-Cell entries indicate the percentage of total behavior occurring during the light $(L)$, the tone $(T)$, and intervening 5 -sec trace intervals on light-tone compound trials in the last block of discrimination training. In Group 0, light and tone presentations were simultaneous.

method (and an experimentwise error of $p<.05$ ) showed that Group 0 showed less head-jerk behavior than did each of Groups 10, 15, and 20. Although the very conservative Miller tests showed no reliable differences between Group 5 and the other groups, individual Mann-Whitney tests at the $\mathrm{p}<.02$ level suggested that Group 5 showed more head-jerk behavior than Group $0(U=10)$ but less than each of the other groups (Us $<10.5$ ). Furthermore, head-jerk behavior was more frequent in response to $\mathrm{T}+$ than to $\mathrm{T}-$ in all groups (Ts $=0$; experimentwise error, $p<.025)$ except Group $0(T=12)$. Head-jerk behavior in response to $\mathrm{T}-$ did not differ among the groups.

The center panels of Figure 5 show magazine behavior in response to $\mathrm{T}+$ (left) and $\mathrm{T}-$ (right). As in Experiment 2, that behavior was rapidly acquired in response to both $\mathrm{T}+$ and $\mathrm{T}-$ and then showed gradual losses in all groups except Group 5. The frequency of magazine behavior in response to $\mathrm{T}+$ differed among the groups $(H=22.42)$; subsequent individual comparisons using Miller's procedure showed magazine behavior to be more frequent (experimentwise error, $p<.05$ ) in Group 5 than in Groups 0, 15, and 20; although not reliable with the conservative Miller procedure, the Group 5 vs. Group 10 difference was reliable at the $\mathrm{p}<.02$ level using a Mann-Whitney test $(U=10)$. Only Group 5 showed reliably more magazine behavior during $T+$ than during $T-(T=2$; experimentwise error, $p<.05$ ). There were no differences among the groups in magazine behavior in response to $\mathrm{T}-$.

The bottom panels of Figure 5 show startle responding to $\mathrm{T}+$ (left) and $\mathrm{T}-$ (right). As in Experiment 2, the tones did not evoke that response by the end of training. There were no differences among the groups in the frequency of that behavior in response to either $\mathrm{T}+$ or $\mathrm{T}-$.

\section{Discussion}

Although the interval between the light and reinforced tone stimuli had little effect on the ability of the light to evoke conditioned rear behavior, that interval had substantial effects on the ability of the tone to evoke conditioned head-jerk behavior on light-tone trials. Simultaneous presentation of tone and light on reinforced trials (Group 0) resulted in the acquisition of rear behavior alone in response to that compound, suggesting that only the light acquired conditioning in that case. This acquisition of behavior in response only to the more predictive feature stimulus is consistent with the results of Experiment 1 . Conversely, insertion of a trace interval between the light feature and tone common elements resulted in the acquisition of substantial head-jerk behavior in response to the tone within the compound. Thus, as in Experiment 2, with longer feature-common element intervals, the light appeared to acquire a conditional, "occasion-setting" function in addition to its ability to evoke a conditioned response. Finally, serial presentation of light and tone stimuli with no intervening trace (Group 5) resulted in some tendency for the light to set the occasion for responding to the tone, but less than that with longer intervals.

Two features of the data of Experiment 3 suggest that associations were also formed between the light and tone elements. First, as outlined in Experiment 2, startle responding did not develop in response to the auditory stimuli that otherwise showed evidence of conditioned responding. Second, by the end of training in the trace groups, head-jerk behavior occurred immediately prior to tone presentation on light-tone trials (Table 3). This control of moderate levels of head-jerk behavior by the light (not seen when visual stimuli are paired with food delivery after trace intervals not including tone stimuli, e.g., Holland, 1980) might be anticipated if light-tone associations were present. Evocation of a representation of the tone might in turn result in the display of tone-specific behavior. Significantly, Holland and Ross (1981) have presented evidence that such associations are indeed involved in nondiscriminative light-tone serial conditioning (see also Wickens, Born, \& Wickens, 1963).

\section{GENERAL DISCUSSION}

Rats successfully solved a variety of feature-positive discriminations but displayed quite different patterns of behavior depending on the temporal arrangement of the feature and common elements (and/or the unconditioned stimulus). When feature and common elements were presented simultaneously, rats acquired only behaviors characteristic of the more predictive feature stimulus. But, when the feature stimulus preceded the stimulus common to both reinforced and nonreinforced trials, the less predictive common element also acquired conditioned responding on compound trials. The form of the behavior in response to the common element indicated that it was itself 

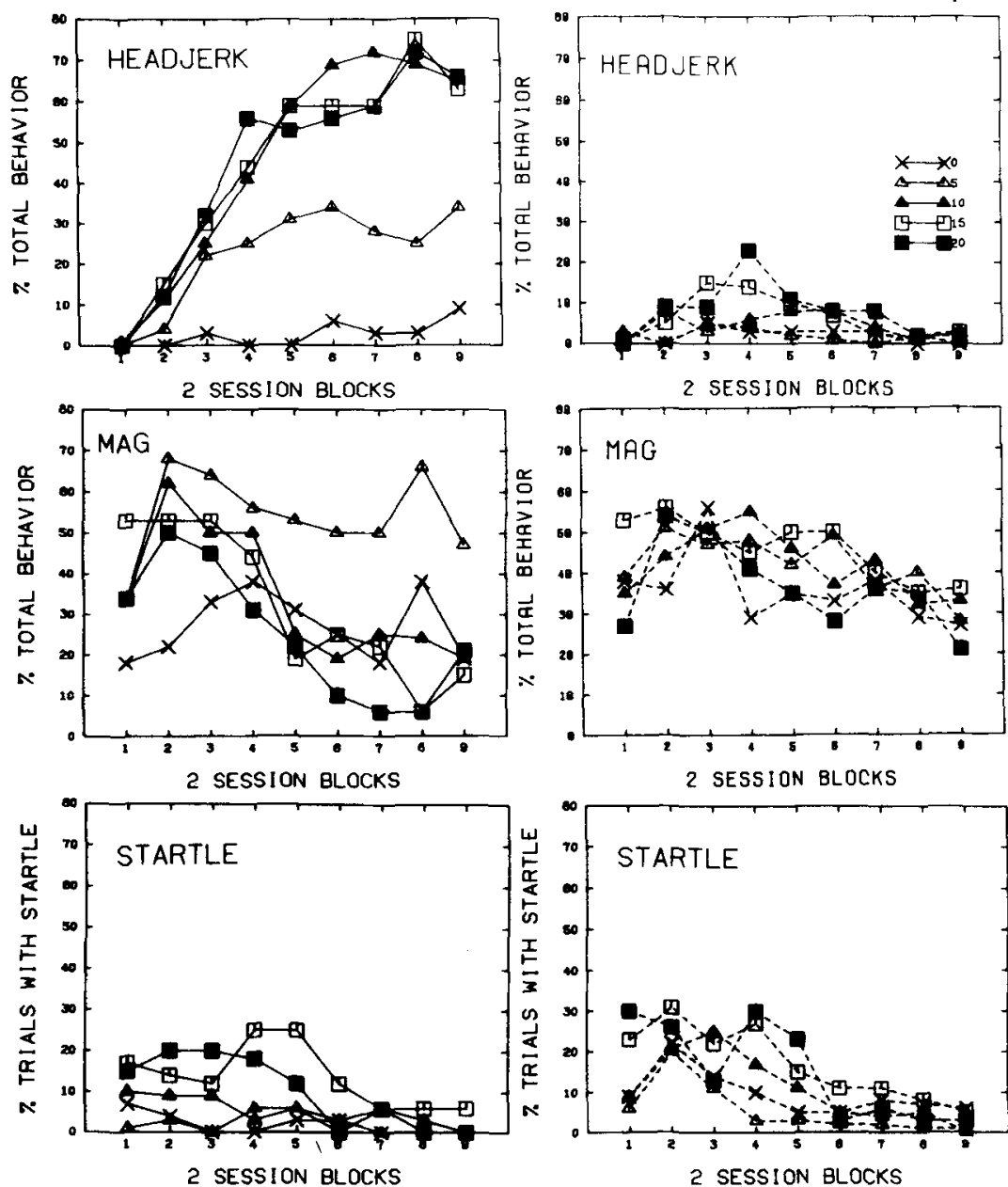

Figure 5. Behaviors in response to the tone on light-tone trials $(T+$, left panebs) and on tone-alone trials ( $T$-, right panels) in Experiment 3 .

conditioned and did not simply "release" (Konorski, 1967) behaviors conditioned to the more predictive feature stimulus. Thus, if conditioning to a more predictive stimulus is discouraged by relatively unfavorable contiguity with the US, and a more contiguous but relatively less predictive stimulus is available, rats seem to use the more predictive stimulus as a conditional cue to "set the occasion" (Moore et al., 1969) for responding to the more contiguous stimulus.

Accounts of performance in complex discriminations that propose additional functions for stimuli (such as occasion-setting) are frequently contrasted with approaches that propose the existence of new stimuli (cf. Carter \& Werner, 1978). Suppose that in Experiment 2 and the serial groups of Experiment 3, the rats abstracted three stimuli: light, which is followed by delayed reinforcement; tone, which is never followed by reinforcement; and the compound "light aftereffects + tone," which is consistently followed by immediate reinforcement. The relation of these three stimuli to the US would suggest that, asymptotically, the tone would evoke little responding, the light would evoke some behavior, and the compound would evoke considerable behavior. Since the behavior evoked by the compound differed from that evoked by either the tone alone or the aftereffects of the light alone, the compound must possess some stimulus unique to that compound. That stimulus is likely to be more similar to the tone than to the light, however, since the tone is physically present at the time of response evocation. Thus, it is reasonable that responding to that compound would be characteristic of auditory rather than visual stimuli.

The present data do not unambiguously favor an occasion-setting over a unique-cue account, but we prefer the former. It seems reasonable to assume that any interaction of light aftereffects and the tone to form a cue unique to the compound would be greater when short, rather than long, light-tone intervals were used. But, in Experiment 3, the pattern of data we describe as indicating occasion-setting occurred most clearly when that interval was long. One might argue that the compound was more like the tone (and hence more likely to evoke head-jerk behavior) when 
the salience of the light aftereffects was smallest or that the compound cue was most likely to control behavior when overshadowing by the light was minimized. But, these claims demand that the shortinterval discriminations be considerably easier to learn than the long-interval discriminations. Experiment 3 indicated no such difference.

It is worth noting the resemblance of these experiments to recent investigations of discriminative stimuli by Jenkins (1977) and by Mackintosh and Dickinson (1979). Skinner's (1938) description of a discriminative stimulus as a stimulus that sets the occasion for reinforcement of a particular response is certainly analogous to our description of the feature stimulus as setting the occasion for the reinforcement of the common element in serial feature-positive discriminations. The two descriptions differ in that the discriminative stimulus is said to set the occasion for a response-reinforcer relation, but the feature stimulus sets the occasion for a stimulus-reinforcer relation. Jenkins noted that since, in operant conditioning experiments, the discriminative stimulus is also directly correlated with the delivery of reinforcement, it may control behavior both because of that relation and because of (or instead of) its more complex, three-term conditional relation with responding and reinforcement. In an attempt to examine the role of the three-term relation alone, Jenkins degraded the stimulus-reinforcer relation by giving separate presentations of the reinforcer in the absence of the discriminative stimulus. We degraded the relation between the feature stimulus and the US by extending the temporal interval between those events; only when the simple relation was degraded did evidence for the conditional, occasion-setting relation emerge. Even more substantial occasion-setting might be demonstrated if the relation between the feature stimulus and the US were further degraded by separate presentations of the food US or by separate nonreinforced presentations of the feature stimulus, as in a positive patterning discrimination.

Finally, it is important to recognize that we are suggesting that there are multiple sources of responding in the serial feature-positive discriminations studied here. First, the acquisition of a conditional, occasionsetting function in response to the light feature permitted the generation of head-jerk behavior by tonefood associations. Second, associations between the light and food resulted in the display of rear and magazine behaviors during the light and subsequent trace intervals. Third, associations between the light and tone may have produced head-jerk behaviors during the trace intervals and caused suppression of startle responding to the tone. The importance of each of these potential contributors to discrimination performance was affected by the light-tone (or light-food) interval; in simultaneous discriminations, only feature-reinforcer associations played an important role. Note, too, that the identification of such multiple sources of behavior was made possible by the use of a conditioning preparation in which those sources generate topographically distinct conditioned behaviors. Other serial feature-positive discrimination experiments (e.g., Hearst, 1978; Kosiba \& Logan, 1978) have left us in doubt as to whether responding on compound trials is elicited by the feature, controlled by the feature but "released" by the common element, or the result of some configural or occasion-setting process. The preparation used in the present experiments should prove useful in studying the nature of performance in complex discriminations.

\section{REFERENCES}

Bottuen, S. W., \& Hearst, E. Food delivery as a conditional stimulus: Feature-learning and memory in pigeons. Journal of the Experimental Analysis of Behavior, 1979, 31, 189-207.

Carter, D. E., \& Werner, T. J. Complex learning and information processing by pigeons: A critical analysis. Journal of the Experimental Analysis of Behavior, 1978, 29, 565-601.

HEARST, E. Stimulus relationships and feature selection in learning and behavior. In S. Hulse, H. Fowler, \& W. K. Honig (Eds.), Cognitive processes in animal behavior. Hillsdale, N.J: Erlbaum, 1978.

Holland, P. C. Conditioned stimulus as a determinant of the form of the Pavlovian conditioned response. Journal of Experimental Psychology: Animal Behavior Processes, 1977, 3, 77-104.

Holland, P. C. CS-US interval as a determinant of the form of Pavlovian appetitive conditioned responses. Journal of Experimental Psychology: Animal Behavior Processes, 1980, 6, 155-174.

Holland, P. C. "Occasion-setting" in conditional discriminations. In M. Commons, R. Herrnstein, \& A. R. Wagner (Eds.), Quantitative analyses of behavior (Vol. 4): Discriminative processes. New York: Ballinger, in press.

Holland, P. C., \& Ross, R. T. Within-compound associations in serial compound conditioning. Journal of Experimental Psychology: Animal Behavior Processes, 1981, 7, 228-241.

Hollander, M., \& Wolfe, D. A. Nonparametric statistical methods. New York: Wiley, 1973.

Jenkins, H. M. Sensitivity of different response systems to stimulus-reinforcer and response-reinforcer relations. In $\mathrm{H}$. Davis \& H. M. B. Hurwitz (Eds.), Operant-Pavlovian interactions. Hillsdale, N.J: Erlbaum, 1977.

Jenkins, H. M., \& Sainsbury, R. S. The development of stimulus control through differential reinforcement. In N. J. Mackintosh \& W. K. Honig (Eds.), Fundamental issues in associative learning. Halifax: Dalhousie University Press, 1969.

Kehoe, E. J., Gibbs, C. M., Garcia, E., \& Gormezano, I. Associative transfer and stimulus selection in classical conditioning of the rabbit's nictitating membrane response to serial compound CSs. Journal of Experimental Psychology: Animal Behavior Processes, 1979, 5, 1-18.

Konorski, J. Integrative activity of the brain. Chicago: University of Chicago Press, 1967

Kosiba, R., \& Logan, F. A. Differential trace conditioning to temporal compounds. Animal Learning \& Behavior, 1978, 6, 205-208.

Looney, T. S., \& Griffin, R. W. A sequential feature-positive effect using tone as the distinguishing feature in an autoshaping procedure. Animal Learning \& Behavior, 1978, 6, 401-405.

Mackintosh, N. J. A theory of attention: Variations in the associability of stimuli with reinforcement. Psychological Review, 1975, 82, 276-298. 
Mackintosh, N. J., \& Dickinson, A. Instrumental (Type II) conditioning. In A. Dickinson \& R. A. Boakes (Eds.), Mechanisms of learning and motivation. Hillsdale, N.J: Erlbaum, 1979.

Moone, J. W., Newman, F. L., \& Glasgow, B. Intertrial cues as discriminative stimuli in human eyelid conditioning. Journal of Experimental Psychology, 1969, 79, 319-326.

Razran, G. H. S. Mind in evolution: East-West synthesis. New York: Houghton Mifflin, 1971.

Rescorla, R. A. "Configural" conditioning in discrete trial barpressing. Journal of Comparative and Physiological Psychology, 1972, 79, 307-317.

Rescorla, R. A., \& W Agner, A. R. A theory of Pavlovian conditioning: Variations in the effectiveness of reinforcement and nonreinforcement. In A. Black \& W. F. Prokasy (Eds.), Classical conditioning II. New York: Appleton-Century-Crofts, 1972.
SkINNER, B. F. The behavior of organisms. New York: AppletonCentury, 1938.

Terry, W. S., \& W Agner, A. R. Short-term memory for "surprising" vs. "expected" unconditioned stimuli in Pavlovian conditioning. Journal of Experimental Psychology: Animal Behavior Processes, 1975, 1, 122-133.

WAGNER, A. R. Expectancies and the priming of STM. In S. H. Hulse, H. Fowler, \& W. K. Honig (Eds.), Cognitive processes in animal behavior. Hillsdale, N.J: Erlbaum, 1978.

Wickens, D. D., Born, D. G., \& Wickens, C. D. Response strength to a compound conditioned stimulus and its elements as a function of the element interstimulus interval. Journal of Comparative and Physiological Psychology, 1963, 56, 727-731.

(Received for publication September 8, 1980; revision accepted February 23, 1981.) 